\title{
Article \\ Spaceflight Modulates the Expression of Key Oxidative Stress and Cell Cycle Related Genes in Heart
}

\author{
Akhilesh Kumar ${ }^{1,+}$, Candice G. T. Tahimic ${ }^{2,+}{ }^{,}$Eduardo A. C. Almeida ${ }^{1}$ and Ruth K. Globus ${ }^{1, *}$ \\ 1 Space Biosciences Division, NASA Ames Research Center, Mail Stop 288-2, Moffett Field, CA 94035, USA; \\ akhilesh482@gmail.com (A.K.); e.almeida@nasa.gov (E.A.C.A.) \\ 2 Department of Biology, University of North Florida, Jacksonville, FL 32224, USA; c.tahimic@unf.edu \\ * Correspondence: ruthglobus@yahoo.com \\ + Equal contribution.
}

check for

updates

Citation: Kumar, A.; Tahimic, C.G.T.;

Almeida, E.A.C.; Globus, R.K.

Spaceflight Modulates the Expression

of Key Oxidative Stress and Cell

Cycle Related Genes in Heart. Int. J.

Mol. Sci. 2021, 22, 9088. https://

doi.org/10.3390/ijms22169088

Academic Editors: Melpo

Christofidou-Solomidou and

Thomas J. Goodwin

Received: 15 July 2021

Accepted: 19 August 2021

Published: 23 August 2021

Publisher's Note: MDPI stays neutral with regard to jurisdictional claims in published maps and institutional affiliations.

Copyright: (c) 2021 by the authors. Licensee MDPI, Basel, Switzerland. This article is an open access article distributed under the terms and conditions of the Creative Commons Attribution (CC BY) license (https:/ / creativecommons.org/licenses/by/ $4.0 /)$.

\begin{abstract}
Spaceflight causes cardiovascular changes due to microgravity-induced redistribution of body fluids and musculoskeletal unloading. Cardiac deconditioning and atrophy on Earth are associated with altered Trp53 and oxidative stress-related pathways, but the effects of spaceflight on cardiac changes at the molecular level are less understood. We tested the hypothesis that spaceflight alters the expression of key genes related to stress response pathways, which may contribute to cardiovascular deconditioning during extended spaceflight. Mice were exposed to spaceflight for 15 days or maintained on Earth (ground control). Ventricle tissue was harvested starting $\sim 3 \mathrm{~h}$ post-landing. We measured expression of select genes implicated in oxidative stress pathways and Trp53 signaling by quantitative PCR. Cardiac expression levels of 37 of 168 genes tested were altered after spaceflight. Spaceflight downregulated transcription factor, Nfe2l2 (Nrf2), upregulated Nox1 and downregulated Ptgs2, suggesting a persistent increase in oxidative stress-related target genes. Spaceflight also substantially upregulated Cdkn1a ( 21$)$ and cell cycle/apoptosis-related gene Myc, and downregulated the inflammatory response gene Tnf. There were no changes in apoptosis-related genes such as Trp53. Spaceflight altered the expression of genes regulating redox balance, cell cycle and senescence in cardiac tissue of mice. Thus, spaceflight may contribute to cardiac dysfunction due to oxidative stress.
\end{abstract}

Keywords: spaceflight; microgravity; heart; gene expression; oxidative stress; $N f e 2 l 2 ; \mathrm{NADPH}$ oxidase; Ptgs2; Cdkn1a; Myc

\section{Introduction}

Responses to spaceflight include cardiovascular deficits, loss of bone and muscle mass, compromised immune function, chromosomal aberrations and metabolic changes [1-3]. With future lunar and interplanetary space missions, astronauts will stay in space for longer periods, presenting increased cardiovascular risk to the crew. Therefore, a better understanding of molecular mechanisms that mediate physiological responses to the space environment is needed.

Entering into microgravity causes a cephalad shift of body fluids which leads to increased heart stroke volume, a rise in left ventricular end diastolic dimensions and a fluid shift between the vasculature and interstitium [4-6]. The fluid shift invokes compensatory endocrine and renal mechanisms [6]. These alterations can diminish the capability of the heart to cope with gravitational stress immediately after returning to Earth, leading to orthostatic intolerance, as previously documented in some astronauts [7].

Gravitational unloading in space also contributes to cardiovascular deconditioning [8], despite vigorous on-orbit exercise programs implemented on the International Space Station (ISS). Both spaceflight and head-down-tilt bed rest, a ground-based model for human spaceflight, can cause reduced plasma volume and left ventricular atrophy $[9,10]$. A reduction in myocardial interstitial fluid may contribute to lower myocardial mass 
following microgravity exposure [11]. In rodents, 14 days of spaceflight was reported to reduce cardiac myocyte size relative to ground controls, which is consistent with cardiac atrophy [12]. In contrast, spaceflight for one week did not affect cardiac mass [13], although it is possible that this period is too short to cause demonstrable cardiac atrophy. Hindlimb unloading (HU), a ground-based rodent model for simulating weightlessness, is reported to cause cardiac atrophy in some studies [14,15], but not in others [13], thus further work in this area is needed.

In addition to gravitational unloading, long term habitation in space will expose astronauts to low doses of ionizing radiation, which may contribute to both cardiac and vascular changes in oxidative pathways leading to tissue dysfunction [16-18]. In fact, spaceflight can cause substantial changes in expression of genes and biomarkers related to metabolic and oxidative stress pathways in various tissues of both astronauts and animals [19-27]. The relative contributions of the various complex factors of habitation in space, including microgravity and ionizing radiation, to observed changes in oxidative stress-related pathways are not yet understood.

Activation of cell cycle arrest and apoptosis signal transduction pathways are major stress responses important for defending against many physiological and environmental challenges, including tissue oxidative stress. Spaceflight can alter expression of various cell cycle arrest and apoptosis regulatory genes [28,29] including CDKN1A (also known as P21), a cyclin dependent kinase inhibitor that mediates cell cycle arrest via cyclin interactions and apoptosis via TRP53. In addition, CDKN1A/P21 is a negative regulator of tissue regeneration in mammals, and is known to interact with NFE2L2 (aka NRF2), a master transcriptional regulator of oxidative defense genes. Spaceflight elevates $C d k n 1 a$ expression in bone tissue [30], liver and kidney [31] as well as cultured cells [29], implicating activation of CDKN1A as a pathway invoked in multiple tissues in response to the space environment.

We hypothesized that spaceflight leads to activation of oxidative stress and cell cycle/apoptosis-related pathways in the heart. To begin to test this hypothesis, we used thematic PCR arrays to identify the changes in expression levels of genes related to oxidative stress and cell cycle/apoptosis (Trp53) signal transduction pathways in mice exposed to 15 days of spaceflight on the STS-131 space shuttle mission. Our gene expression findings in heart are novel and consistent with activation of several molecular pathways, including those related to oxidative stress, cell cycle regulation, inflammation and DNA damage repair, which ultimately may contribute to cardiac dysfunction during long duration spaceflight.

\section{Results}

\subsection{Body Mass of Animals Pre-and Post-Flight}

Immediately after landing, all flight (FLT) and ground (GRD) control mice were determined to be in good condition by veterinary examination. Figure 1 shows the schematic of the experiment design and workflow. The average weight loss of FLT mice over the duration of the experiment was $2.0 \mathrm{~g}(-9.1 \%, \mathrm{SD}=2.1 \mathrm{~g}, p=0.013)$ whereas GRD control mice lost an average of $0.7 \mathrm{~g}(-3.4 \%, \mathrm{SD}=0.9 \mathrm{~g}, p=0.096)$; the difference in body weight loss averages for FLT versus GRD was not significant $(p=0.143)$. FLT habitats showed an average of $10 \%$ less food remaining, and $24 \%$ less water remaining than GRD habitats. However, measured values for food and water utilization after flight may not precisely reflect actual consumption by mice due to possible differences in food breakdown and water spillage in FLT versus GRD habitats.

\subsection{Spaceflight Altered Expression of Oxidative Stress Related Genes}

Comparable quantities (average of $38.5 \mu \mathrm{g}$ RNA per tissue sample) and high qualities of total RNA were obtained from all the FLT and GRD samples. To determine if spaceflight altered the expression of genes regulating redox balance in cardiac tissue, oxidative stress PCR array was performed on 84 genes related to oxidative metabolism (Supplementary Table S1), and this data set was supplemented with real time PCR analysis of Nfe2l2 

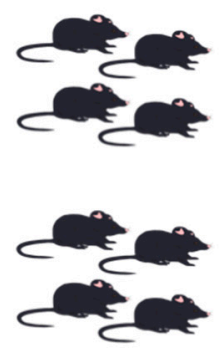

Fourteen-week old Female C57BL/6J Mice expression levels (Figure 2). Gene expression levels of FLT and GRD controls showed a trend towards upregulation of a majority of those genes which were altered by spaceflight (Table 1). Out of the 84 genes on the array, 11 genes were upregulated and 3 genes were downregulated in FLT samples relative to GRD $(p<0.05)$ (Table 1$)$.

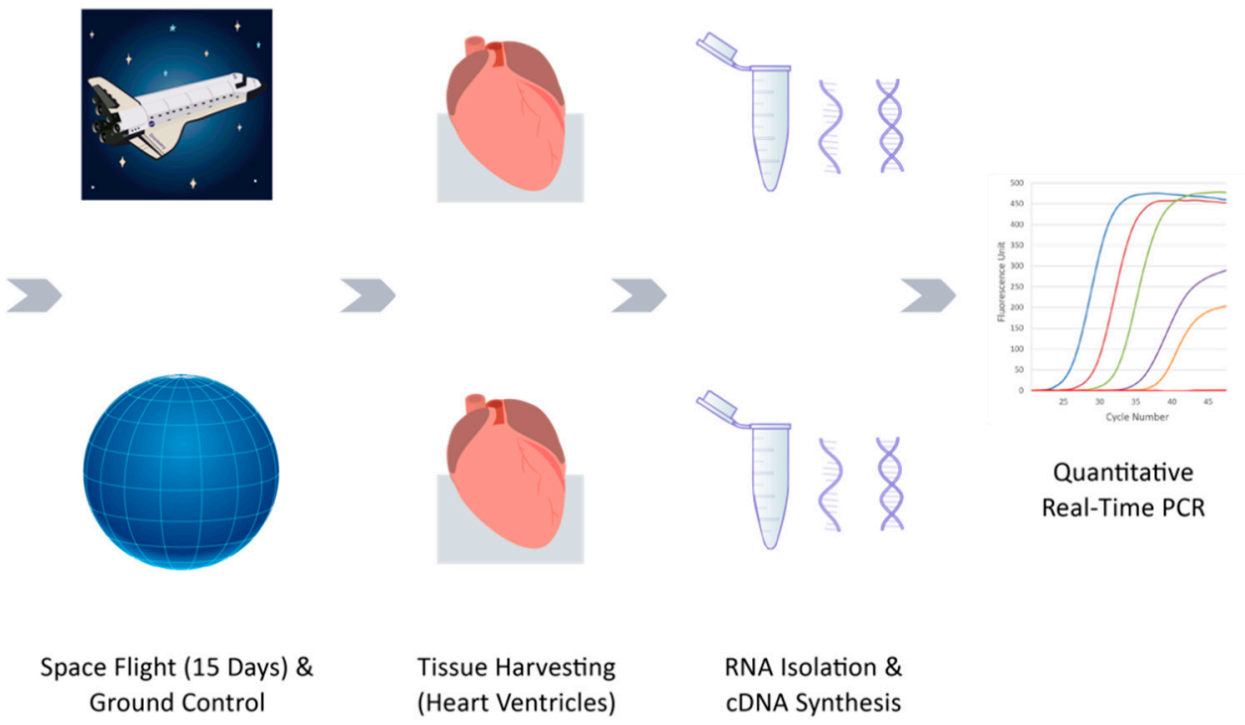

Figure 1. Schematic diagram of experiment design and workflow.

Table 1. Spaceflight altered the expression of genes involved in oxidative stress pathway. Expression levels are represented as fold regulation in spaceflight versus ground controls (FLT versus GRD). Shown are 14 differentially regulated genes out of a panel of 84 genes related to the oxidative stress response as measured by RT-PCR. Of these, 11 were upregulated while three were downregulated. The change in expression levels of these genes were found to be statistically significant by MannWhitney U test at $p<0.05, \mathrm{n}=4$.

\begin{tabular}{llc}
\hline \multicolumn{1}{c}{ Gene Symbol } & \multicolumn{1}{c}{ Gene Name } & Fold Regulation \\
\hline Nox1 & NADPH oxidase 1 & 6.62 \\
Tpo & Thyroid peroxidase & 2.35 \\
Slc41a3 & Solute carrier family 41, member 3 & 1.97 \\
Txnip & Thioredoxin interacting protein & 1.94 \\
Prnp & Prion protein & 1.44 \\
Txnrd3 & Thioredoxin reductase 3 & 1.43 \\
Gsr & Glutathione reductase & 1.31 \\
Prdx6 & Peroxiredoxin 6 & 1.23 \\
Cat & Catalase & 1.20 \\
Xpa & Xeroderma pigmentosum, & 1.18 \\
Sod1 & complementation group A & 1.18 \\
Ncf2 & Superoxide dismutase 1, soluble & -1.49 \\
Fancc & Neutrophil cytosolic factor 2 & -1.62 \\
Ptgs2 & Fanconi anemia, complementation & -3.44 \\
\hline
\end{tabular}

Specifically, there was a marked 6.6-fold upregulation in expression of NADPH oxidase 1 (Nox1), suggesting an increase in production of superoxide and/or hydrogen peroxide. Additionally, expression of Prostaglandin endoperoxidase synthase 2 (Ptgs2), which acts as peroxidase, was downregulated by 3.4-fold. The upregulation of Nox1 and downregulation of Ptgs 2 may reflect elevated oxidative stress within heart tissue of FLT mice relative to GRD controls. In addition, Txnip was upregulated by 1.9-fold and Fancc was downregulated 1.6-fold in FLT samples. Ncf2, which codes for a component of the 
NADPH oxidase complex that generates superoxide, was moderately downregulated by spaceflight (-1.5-fold). Other antioxidant genes (Sod1, Cat, Prdx6, Gsr, Tpo, Txnrd3, Slc41a3) and oxidative stress-responsive genes (Xpa, Prnp) were moderately affected by spaceflight $(1.2-2.4$ fold,$p<0.05)$ (Table 1). There were no changes in the expression levels of 12 genes related to oxygen transport (Supplementary Table S1). In contrast, there was a 2.4-fold reduction in expression of the global transcription factor, Nfe2l2, in FLT compared to GRD animals (Figure 2). Thus, the expression of redox-related genes was differentially regulated as a consequence of exposure to the spaceflight environment.

\section{$\mathrm{Nfe} 212$}

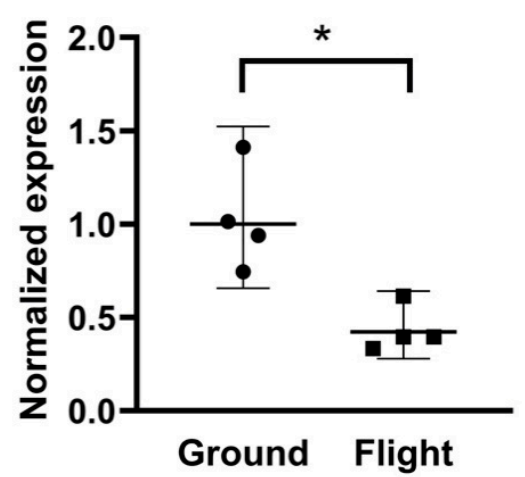

Figure 2. Normalized expression levels of $\mathrm{Nfe} 2 l 2$ as measured by a separate RT-PCR assay. Each data point is shown. The middle lines indicate the geometric mean (normalized expression of 1 for Ground Control and 0.42 for Spaceflight group). Outer lines show the 95\% confidence intervals. * Statistically significant by Mann-Whitney U test at $p<0.05, \mathrm{n}=4$. The log2 (linear) normalized expression from the Ground Control and Flight groups were used in the Mann-Whitney U test.

\subsection{Spaceflight Altered Expression of Cell Cycle/Proliferation Related Genes}

The expression levels of 84 genes involved cell cycle and apoptosis signal transduction were analyzed by $p 53$ Signaling Pathway PCR array (Supplementary Table S2). Out of 84 genes, 13 genes were upregulated and 10 genes were downregulated in FLT compared to GRD controls (Table 2, $p<0.05$ ). Results show that genes related to cell cycle regulation were altered due to spaceflight. Specifically, cell cycle inhibitors such as $C d k n 1 a$ were upregulated 6.8-fold while $C d k 1$ was downregulated 4.1-fold, suggesting diminished growth and proliferation signals in FLT samples compared to GRD. Myc was upregulated 3.9-fold $(p<0.05)$. Genes involved in inflammatory responses, including Tnf, Tnfrsf10b (Tnf receptor superfamily, member 10) and Traf1, were downregulated (9.9-, 1.9- and 2.3-fold decrease, respectively) in spaceflight samples. Out of the 14 genes analyzed for DNA damage repair, four genes were modestly upregulated (Atr, Xrcc5, Ercc1, Apex1; 1.1-1.3-fold) (Table 2, $p<0.05)$. There were no significant changes in apoptosis-related genes including Trp53, Bax, Bcl2, Casp2 or Casp9 (Supplementary Table S2).

\subsection{Gene Networks and Disease Predictions}

We made use of a computational approach to gain insight into possible protein-protein interactions among the differentially expressed genes. Analysis using String Db revealed potential interactions between the oxidative stress response and Trp53 pathways (Figure 3). A number of oxidative stress response DEGs formed a molecular interaction network including Nox1 and Sod1 with Catalase serving as a central node. DEGs from the Trp53 signaling pathway also formed molecular interaction networks involving cell cycle-related genes and transcription factors. For the Trp53 pathway, Cdk1, Cdk4, Cdkn1a and Atr served as central nodes in a molecular network that included Chek2, Fancc, Ercc1, Xrcc5 and Xpa1 among others. Interestingly, the oxidative stress response and Trp53 pathways were linked by central nodes FoxO3, Jun, Myc, and Hif1a, all of which code for major transcriptional 
regulators. This finding suggests global transcriptomic changes in the heart response to spaceflight.

Table 2. Spaceflight altered the expression of genes involved in the Trp53 signaling pathway. Expression levels are represented as fold regulation in spaceflight versus ground controls (FLT versus GRD). Shown are 23 differentially regulated genes out of a panel of 84 genes related to the Trp53 signaling pathways as assessed by RT-PCR. Out of these, 13 genes were upregulated and 10 genes were downregulated. The change in expression levels of these genes were found to be statistically significant by Mann-Whitney $\mathrm{U}$ test at $p<0.05, \mathrm{n}=4$.

\begin{tabular}{llc}
\hline \multicolumn{1}{c}{ Gene Symbol } & \multicolumn{1}{c}{ Gene Name } & Fold Regulation \\
\hline Cdkn1a & Cyclin-dependent kinase inhibitor 1A (P21) & 6.80 \\
Myc & Myelocytomatosis oncogene & 3.91 \\
Hif1a & Hypoxia inducible factor 1, alpha subunit & 1.58 \\
Pmaip1 & Phorbol-12-myristate-13-acetate-induced & 1.54 \\
Prkca & protein 1 & 1.49 \\
Trp53bp2 & Protein kinase C, alpha & 1.41 \\
Apex1 & Transformation related protein 53 binding & 1.28 \\
& protein 2 & \\
Ercc1 & Apurinic/apyrimidinic endonuclease 1 & 1.27 \\
& Excision repair cross-complementing rodent & \\
Foxo3 & repair deficiency, & 1.27 \\
Mlh1 & complementation group 1 & 1.19 \\
Pten & Forkhead box O3 & 1.18 \\
Xrcc5 & MutL homolog 1 (E. coli) & 1.13 \\
Atr & Phosphatase and tensin homolog & 1.10 \\
Cdk4 & X-ray repair complementing defective repair in & -1.16 \\
Apaf1 & Chinese hamster cells 5 & -1.41 \\
Tnfrsf10b & Ataxia telangiectasia and rad3 related & -1.92 \\
Chek2 & Cyclin-dependent kinase 4 & -2.15 \\
Traf1 & Apoptotic peptidase activating factor 1 & -2.25 \\
Jun & Tumor necrosis factor receptor superfamily, & -2.31 \\
Pttg1 & member 10b & -2.42 \\
Btg2 & CHK2 checkpoint homolog (S. pombe) & -3.50 \\
Cdk1 & Tnf receptor-associated factor 1 & -4.11 \\
Tnf & Jun oncogene & -9.86 \\
\hline & Pituitary tumor-transforming gene 1 & \\
\hline & B-cell translocation gene 2, anti-proliferative & \\
\hline Cyclin-dependent kinase 1 & Tumor necrosis factor & \\
& &
\end{tabular}

We also utilized a computational approach to gain insight into possible disease phenotypes associated with spaceflight-induced changes in gene expression. Functional enrichment analysis of oxidative stress array DEGs using Toppfun revealed enrichment of genes linked to hypertensive disease, atherosclerosis, cerebrovascular accident and decompensation (Supplementary Table S3). Using a similar analysis approach, p53 array DEGs revealed potential links to a number of cancers including sarcoma, immune suppression, impaired glucose tolerance and cardiovascular pathologies including hypertensive disease, acute myocardial infarction, and atherosclerosis (Supplementary Table S4). 


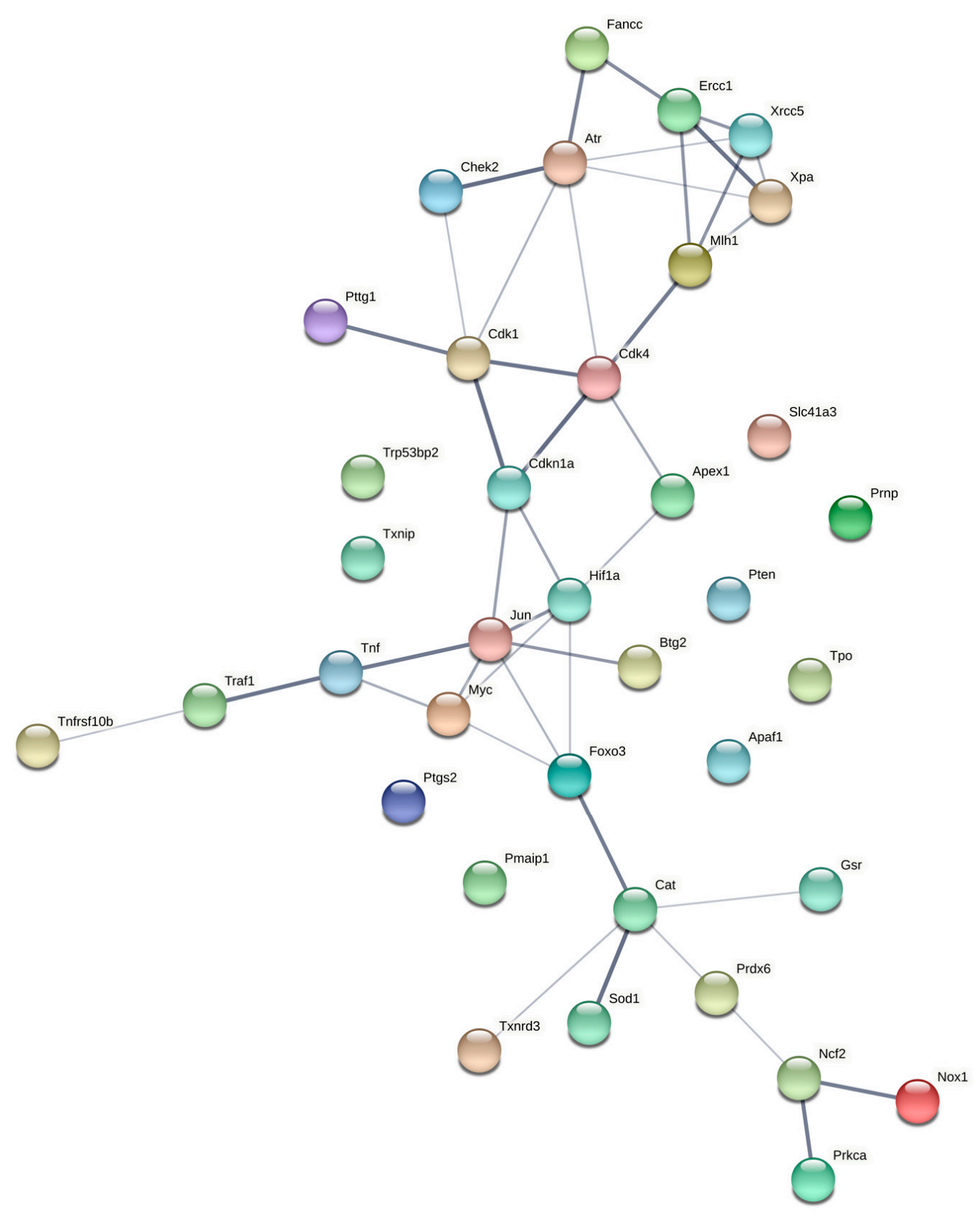

Figure 3. Predicted molecular interactions among DEGs from an oxidative stress PCR Array and p53 Signaling Pathway PCR Array using String Db (Refer to the Methods section for details on analysis). Thicker lines connecting genes represent greater confidence in molecular interactions.

\section{Discussion}

Our findings provide new insight into how the heart responds at the molecular level to the novel environment of space. Spaceflight experiments using rodents present unique practical challenges though similar benefits to rodent studies on Earth. The animals flown in space during this particular mission were deemed healthy, as assessed by veterinary examination after return to Earth, and the finding that animal body weights were comparable in FLT mice compared to GRD controls at the termination of the study. Further, numerous scientific reports from these mice describe related results obtained studying other organ systems (e.g., [30,32,33]). The RNA samples recovered from the hearts were consistent and of high quality. Therefore, we conclude that the results we obtained from this mission were valid. 
Whereas cardiovascular physiology has been studied intensively in astronauts, analysis of cardiac changes at the tissue level has been more limited [12,13,34-36]. Goldstein et al. [12] report that spaceflight (14 days) reduces the cross-sectional area of papillary cardiomyocytes in rats relative to ground controls, with ultrastructural changes consistent with cardiac atrophy. Short duration (6 days) spaceflight upregulates activity and mRNA expression of the mitochondrial enzyme, malate dehydrogenase in rat hearts, and displays a pattern of mitochondrial gene expression changes discrete from those in skeletal muscle [34]. More recently, long duration spaceflight (37 days) was shown to alter expression of methylationrelated genes in the heart of adult mice, but not cytoskeletal protein levels. Interestingly, lifetime exposure of Drosophila to microgravity leads to diminished cardiac size, cardiac dysfunction, altered remodeling, and proteosomal abnormalities [36]. Furthermore, spaceflight causes cardiac progenitor cells in culture to display a gene expression profile consistent with early, stem-like function along with increased oxidative stress and re-entry into the cell cycle [37]. Thus, our study on expression levels of oxidative stress and cell cycle-related genes provides novel findings on how the heart responds to spaceflight at the tissue level.

\subsection{Oxidative Stress-Related Gene Expression in Spaceflight Heart}

RT-PCR array data show that expression levels of 14 genes were significantly $(p<0.05)$ altered (11 upregulated and 3 downregulated) in FLT samples as compared to GRD controls. In addition, RT-PCR analysis for $N f e 2 l 2$ revealed lower levels in FLT mice than GRD. Nfe2l2 is a master transcriptional regulator for oxidative stress response genes, and is rapidly transcribed within seconds following changes in the gravity vector [23]. Other tissues also display reduced $\mathrm{Nfe} 2 \mathrm{l} 2$ expression levels in similar spaceflight experiments entailing tissue recovery after landing [38]. Suzuki et al. recently demonstrated that long duration spaceflight activates $\mathrm{Nfe} 2 \mathrm{l2}$-dependent oxidative stress pathways in several tissues of growing mice [39]. Furthermore, Nfe2l2-deficient mice are protected from spaceflightinduced oxidative stress-related genes and changes in body weight [39], and also display accelerated transition of muscle fiber type without protecting from atrophy [40].

We also found that spaceflight upregulated Nox1 6.6-fold, the change of greatest magnitude in oxidative stress-related genes observed in our study. NOX1 belongs to the NADPH oxidase family of enzymes and functions in generating ROS in a highly regulated fashion [41,42]. NOX1 utilizes NADPH as an electron donor and catalyzes transfer of electrons to molecular oxygen to generate superoxide radicals. Superoxide radicals are short lived and are readily converted into hydrogen peroxide. Thus, increased expression of Nox 1 can cause an increase in the formation of hydrogen peroxide and other reactive oxygen species (ROS) [41,42]. NADPH oxidases are major sources of ROS in the vascular system and are involved in the pathophysiology of many cardiovascular diseases such as hypertension and myocardial infarction [43]. Several recent studies using ground-based models to simulate weightlessness show that hindlimb unloading causes cardiac atrophy, reduces cardiomyocyte size and cardiac dysfunction, as assessed by fractional shortening [14]. Inhibition of NOX1 by apocynin (a NADPH oxidase inhibitor) reduces oxidative stress markers in the heart, and mitigates atrophy and dysfunction in hindlimb unloaded mice, suggesting that Nox1 plays an important role in mediating cardiac responses to simulated weightlessness [44]. Thus, our results support the hypothesis that increased expression of Nox1 during spaceflight contributes to oxidative stress and myocardial abnormalities.

Oxidative stress PCR array results showed lower expression of Ptgs2 by 3.4-fold in FLT samples compared to GRD. PTGS2, also known as Cycloxygenase 2 (COX2), is the key, inducible enzyme in prostaglandin biosynthesis, and acts as both a dioxygenase and as a peroxidase, converting hydrogen peroxide into water. Thus, lower Ptgs 2 expression can lead to inefficient removal of hydrogen peroxide, accumulation of ROS and oxidative damage. PTGS2 is important for the maintenance of healthy cardiac tissue. Conditional cardiomyocyte-specific deletion of the Ptgs2 gene in adult mice reduces cardiac output, decreases exercise tolerance and increases susceptibility to induced ventricular arrhyth- 
mias [45]. Furthermore, human and animal models of myocardial diseases show that Ptgs 2 expression is associated with cardiac tissue damaged by infarction, septicemia and inflammatory heart diseases [46]. In addition to inflammation, the prostaglandin pathway plays an important role in mechanical signaling. In cultured cells activated by serum, spaceflight prevents induction of Ptgs 2 expression, which is avoided by on-orbit centrifugation to replace the gravity vector, implicating sensitivity to a biomechanical mechanism for microgravity-induced activation of the prostaglandin pathway [47]. Inhibition of PTGS2 also impairs recovery of skeletal muscle and bone from hindlimb unloading [48,49]. Thus, regulation of the prostaglandin pathway by spaceflight via changes in Ptgs2 expression may contribute to both oxidative stress and subsequent recovery on Earth.

Txnip was upregulated 1.9-fold and Fancc was downregulated 1.6-fold in FLT compared to GRD, which also may contribute to a pro-oxidative milieu in the heart during spaceflight. TXNIP is a negative regulator of thioredoxins (TRXs) [50], which are potent antioxidants, and their downregulation by elevated Txnip expression in FLT samples may lead to increased oxidative stress in cardiac tissue. In cultured human endothelial cells (HUVEC), Txnip was the most upregulated by spaceflight (33-fold) [51]. Fancc codes for an antioxidant and its downregulation can cause sensitivity to oxidative stress-mediated damage to tissue [52].

Our results indicated moderate changes in several antioxidant genes (Sod1, Cat, Prdx6, Gsr, Tpo, Txnrd3, Slc41a3) and other oxidative stress-responsive genes (Xpa, Prnp) (1.2-2.4-fold, $p<0.05$ ) (Table 1). The observed elevated expression levels of these antioxidant genes may be due to activation of compensatory mechanisms.

Although the magnitude of differences between FLT and GRD for statistically significant genes were generally modest, together, the findings suggest that spaceflight activates a network of genes responsible for redox signaling and defense against oxidative stress in the heart.

\subsection{Cell Cycle and Senescence-Related Gene Expression in Spaceflight Heart}

Increased generation of ROS during spaceflight can lead to protein, lipid and DNA damage in tissue and, as is the case with skeletal muscle, may contribute to dysfunction caused by gravitational unloading. ROS are also involved in vital cell signaling pathways such as cell-cycle progression, differentiation, inflammation and apoptosis. Cell cycle progression in eukaryotes is regulated at various checkpoints by the action of specific cyclin dependent kinases (CDKs). The activities of these CDKs are controlled by the positive regulation from cyclins and negative regulation from cyclin dependent kinase inhibitors (CDKIs). Hence, expression levels of genes involved in cell cycle regulation, inflammation, DNA damage repair and apoptosis were further analyzed in hearts by $p 53$ Signaling PCR array. The $p 53$ Signaling PCR array includes 24 genes involved in cell cycle regulation. Results indicate that nine of these genes were significantly altered in FLT samples.

We found spaceflight increased $C d k n 1 a / \mathrm{p} 21$ expression 6.8-fold in hearts compared to GRD, consistent with reports for other tissues including liver, kidney, bone and muscle $[27,30,31]$. CDKN1A (also known as P21), is a potent CDK inhibitor and inhibits cell cycle progression at the G1 phase by inhibiting the activity of CDK2 or CDK4. Increases in $p 21$ levels in bone from mice in this spaceflight experiment spaceflight were previously associated with proliferative arrest in cultured osteoprogenitors [30]. However, the adult mammalian heart itself has limited regenerative ability. Adult $p 21$ levels in adult heart are thought to contribute to normal cell cycle arrest in differentiated cardiomyocytes, and there is evidence that cardiomyocytes can divide in the adult human heart [53], though it is unlikely that such a small sub-population (1.3\% of total) [53] can account for our findings. More likely, the elevation in $p 21$ caused by spaceflight may contribute to cardiomyopathies [54] via other cellular processes such as DNA repair, autophagy $[38,55,56]$ and senescence. Interestingly, $M y c$, a mitogenic transcription factor gene that promotes cardiac hypertrophy in response to Angiotensin II, was also highly upregulated in the spaceflight heart samples we studied, and its deleterious action can be rescued by $p 21$ 
re-expression in p21-null mice [57]. Finally, in newborn mammals, $p 21$ elevation might interfere with cardiomyocyte binucleation, an important heart growth mechanism during post-natal development [58].

PTTG1 (Pituitary tumor-transforming gene 1) regulates the cell cycle by inducing cyclin D3 and repressing $p 21$ expression [59]. Thus, a decrease in Pttg1 expression (2.4-fold) observed in FLT samples may contribute to the observed increase in expression of $p 21$ in FLT samples. In addition to upregulation of cell cycle inhibitors, CDK's and cyclins such as $C d k 1$ and $C d k 4$ were downregulated in FLT samples, implicating an overall cell cycle arrest in spaceflight samples.

Our results also indicate some apparently contradictory findings, such as the expression levels of genes for cell cycle arrest proteins, Chek2 and Btg2, were decreased 2.2- and 3.5-fold, respectively in FLT samples, contrary to what is expected for Chek2 when Myc is overexpressed based on what is observed in lymphoma cells [60].

Thus, one of the crucial findings of our study is that spaceflight alters the expression levels of major cell cycle and cell growth regulators. As the samples analyzed consist predominantly (but not solely) of fully differentiated non-dividing cardiomyocytes, this suggests that spaceflight activates $p 21$ - and Myc-related pathways to regulate cell growth, cardiomyocyte function, and potentially cardiomyopathy, although complex interactions such as these remain to be elucidated.

\subsection{Apoptosis and DNA Damage Repair-Related Gene Expression in Spaceflight Hearts}

There were no significant changes in apoptosis-related genes such as p53, Bax, Bcl2, Casp2 or Casp9 (Supplementary Table S2). DNA damage repair genes such as Atr, Xrcc5, Ercc1 and Apex1 were only moderately altered in spaceflight (1.1- to 1.3-fold), suggesting widespread DNA damage responses were not occurring at the time of sample recovery. However, we cannot rule out the possibility that spaceflight activates DNA damage and apoptosis pathways in a smaller sub-population of cell types within the heart during spaceflight, as shown previously for exposure to low dose, heavy ion radiation $\left({ }^{16} \mathrm{O}\right.$, $600 \mathrm{MeV} / \mathrm{n}$ ) simulating space radiation [61]. Evidence supporting the possibility that spaceflight activates DNA damage pathways and/or apoptosis has been reported for tissues other than heart [62], including the thymus [63,64] and the eye [62,64], and multiomics analyses reveal increased levels of DNA damage markers in urine and blood from astronauts [26].

\subsection{Inflammatory Pathway Gene Expression in Spaceflight Heart}

Inflammatory response genes, such as Tnf (tumor necrosis factor), Tnfrsf10b (Tnf receptor superfamily, member 10) and Traf1 (Tnf receptor-associated factor) were significantly downregulated (9.9-, 1.9- and 2.3-fold decrease) in FLT samples compared to GRD controls. Tnf is a multifunctional pro-inflammatory cytokine, which regulates a wide variety of biological processes such as inflammation, proliferation, differentiation, apoptosis and cytotoxicity [65]. Space is a hazardous environment and proper immune functioning is crucial for astronaut health and success of space missions. The decreased expression of Tnf, Tnfrsf10b and Traf1 observed in our study suggests downregulation of this pro-inflammatory signaling pathway, which may lead to compromised immune function. Our results are consistent with other studies showing spaceflight reduces Tnf expression levels in both mice [19,66] and humans [67]. In addition, human T cell cultures on the International Space Station (ISS) show a 15-fold decrement in expression of Tnf in T cells and its downstream effectors in microgravity as compared to cells centrifuged at $1 \mathrm{~g}$ [68]. During a very long duration spaceflight, TNF $\alpha$ expression in the blood of astronauts is elevated [24] but after return to Earth (between days 0 and 5) as skeletal muscle enters a recovery phase, $\operatorname{Tnf} \alpha$ expression rapidly declines along with other cytokines in the Il6 pathway [69]. Together, these findings implicate a biomechanical, gravity-dependent mechanism for regulating Tnf-related pathways. 
Although the radiation exposure of mice on the STS-131 mission is considered too low to account for our results, relatively low doses of particle radiation ( $<30 \mathrm{cGy}$ ) can lead to altered regulation of disease-related pathways and deficits in cardiac function $[70,71]$. Furthermore, expression of oxidative stress and inflammation markers in the heart caused by low dose gamma radiation exposure is exacerbated when combined with hindlimb unloading [17]. Further study is needed to determine the influence of space radiation in combination with microgravity, on the heart in the spaceflight environment during long duration missions.

\subsection{Gene Networks and Molecular Signatures of Disease}

Computational analysis revealed that changes in a subset of genes that were differentially expressed due to spaceflight were linked to disease, including immune suppression and impairments in glucose homeostasis, consistent with findings in astronauts [72,73]. In addition, a subset of the DEGs resulting from spaceflight were associated with cardiovascular pathologies such as atherosclerosis, cardiovascular decompensation, hypertensive disease and myocardial infarction. Cardiovascular decompensation and volumetric changes in blood flow were consistent with previous observations in crew members during flight $[3,8,74]$. In a previous study on a subset of ISS crewmembers, mean arterial pressures reportedly do not change significantly during spaceflight. However, cardiac output and stroke volume are increased in flight compared to the seated position on Earth (although comparable to the supine position on Earth) [3]. Thus, our findings were consistent with previous reports on astronauts indicating that spaceflight adversely affects cardiovascular health.

Computational analyses also indicated that spaceflight led to altered regulation of molecular networks within the oxidative damage response and cell proliferation pathways. Our findings suggest that oxidative stress and Trp35 signaling pathways were linked and that spaceflight alters gene interactions between these two pathways. Furthermore, transcription factors FoxO3, Jun, Myc, and Hif1a were predicted to mediate the interaction between these two pathways, making these genes promising targets for mitigating gene network changes in response to spaceflight. Cat, Cdkn1a, Cdk1 and Cdk4 also were predicted to serve as central hubs of gene networks that are altered by spaceflight. Hence, these molecules may be potential targets for the development of countermeasures against spaceflight-induced tissue deficits.

\subsection{Limitations}

For extrapolation of findings from this murine study to humans, there is the inherent limitation of the difference in species as well as a potential influence of the specific strain and sex which were selected as subjects. Factors related to experimental protocol also important to consider when interpreting gene expression findings from this experiment include the fixed duration of the mission (15 days), sample recovery only after animals were returned to Earth (3+ hours after landing), and the fact that ground control animals were housed in flight-matched habitats but were not exposed to similar forces as the flight mice encountered during launch and landing. Therefore, observed changes in gene expression did not solely reflect changes observed during habitation in microgravity, but for rapidly responding genes, such as $N f e 2 l 2$, also may reflect re-entry and re-adaptation to 1-gravity on Earth, however briefly.

As the scope of our investigation focused on RT-PCR, additional studies are needed to elucidate how spaceflight-induced oxidative stress may mediate cell cycle/growth and function, to gain deeper insight into how the cardiovascular system responds to the space environment and recovers after return to Earth. Furthermore, because the heart consists of multiple cell types, including cardiomyocytes, fibroblasts, endothelial cells, and macrophages, each with a discrete gene expression profile [53], future experiments could focus on spatial transcriptomics to determine the cellular source of specific gene expression changes, as well as the regulation of protein expression together with cardiac function. 


\section{Materials and Methods}

\subsection{Ethics Statement}

All animal procedures were conducted in accordance with guidelines described by the National Institute of Health Guide for Care and Use of Laboratory Animals, and approved by all relevant committees, including the Institutional Animal Care and Use Committee (IACUC) at National Aeronautics and Space Administration (NASA) Ames Research Center. The IACUC approval number associated with this animal study was NAS-10-002-Y1.

\subsection{Animals and Spaceflight}

The mice in this study were flown on the Space Shuttle Discovery during the STS-131 mission for the experiment "Mouse Antigen-Specific CD4+ T Cell Priming and Memory Response during Spaceflight". The heart tissue used in this experiment was an award to E. Almeida as part of the NASA STS-131 Mouse Immunology I Biospecimen Sharing Program (BSP). Female C57BL/6J mice were acclimatized to spaceflight food bars and lixits, but were not placed in Animal Enclosure Module (AEM) habitats until just before spaceflight. Mice were divided into two groups: flight (FLT) and ground (GRD) control. The NASA AEM units are composed of a stainless-steel grid cage, fan blowers, a layered filter system, interior lamps, specialized food bars, and a water box. The AEM units are self-contained habitats that provide group housing with constant ad libitum access to food and water while also providing a waste management system that isolates the animals from their waste. FLT mice were launched at 14 weeks of age then flown in space for 15 days and were not subjected to any experimental procedures during spaceflight.

Synchronous GRD control mice were also housed in AEMs, maintained in an orbital environmental simulator at Kennedy Space Center, and exposed to environmental conditions matched closely to those of FLT mice on the shuttle (temperature, light/dark cycle, humidity, and carbon dioxide levels). FLT and GRD control animals were weighed before flight and immediately after return and were subjected to veterinary examination prior to euthanasia. Food and water consumption of each group were measured upon recovery. Animals were euthanized at 16 weeks of age starting approximately $3 \mathrm{~h}$ after landing using isoflurane anesthesia followed by thoracotomy. Euthanasia and dissections proceeded at a pace of one mouse every $15-20 \mathrm{~min}$. The heart was removed and major veins and feed arteries trimmed off. The hearts of four mice per group were bisected into the cephalic and caudal regions, and the caudal halves (ventricles) were frozen in liquid nitrogen for later analysis of gene expression (the remaining hearts from four mice per group were distributed to another BSP investigator). The frozen samples were transported on dry ice to NASA Ames Research Center and stored in liquid nitrogen until analysis.

\subsection{RNA Isolation and cDNA Synthesis}

Total RNA was isolated from frozen heart tissue by homogenization and RNA extraction using TRIzol reagent (Life Technologies, Carlsbad, CA, USA). Tissue samples were homogenized in $1 \mathrm{~mL}$ of TRIzol reagent and incubated at room temperature for $5 \mathrm{~min}$. After incubation, $0.2 \mathrm{~mL}$ of chloroform was added, the sample agitated vigorously for $30 \mathrm{~s}$ and then incubated for $2 \mathrm{~min}$ at room temperature. The mixture was then centrifuged at $12,000 \times g$ for $15 \mathrm{~min}$ at $4{ }^{\circ} \mathrm{C}$. Following centrifugation, the upper aqueous phases were separated and incubated with $0.5 \mathrm{~mL}$ of isopropanol for $10 \mathrm{~min}$ at room temperature. Samples were then centrifuged at $12,000 \times g$ for $15 \mathrm{~min}$ at $4{ }^{\circ} \mathrm{C}$ and the RNA pellet was washed with $70 \%$ ethanol. The RNA pellet was dissolved in $100 \mu \mathrm{L}$ of nuclease-free water and further purified using an RNeasy Mini Kit (Qiagen, Valencia, CA, USA), per instructions. The quantities and qualities of purified RNA were determined by measuring absorbance at $260 \mathrm{~nm}$ and $280 \mathrm{~nm}$ using a NanoDrop 2000 Spectrophotometer (Thermo Scientific, Wilmington, DE, USA). RNA integrity was assessed by running RNA on $0.8 \%$ agarose formaldehyde-denaturing gel with ethidium bromide and further visualized by Fluor-S Multimager (Bio-Rad, Hercules, CA, USA). 
All RNA samples were analyzed by thematic real time PCR arrays (for Oxidative Stress and p53-related pathways) or RT-PCR (for Nfe2l2). Although whole transcriptome analysis would be valuable, samples are no longer available for additional analyses.

\subsection{Quantitative Real-Time PCR Array}

An equal amount of RNA $(1 \mu \mathrm{g})$ was used from FLT and GRD samples to synthesize cDNA using RT ${ }^{2}$ PCR Array First Strand Kit (SABiosciences, Frederick, MD, USA). Real-time PCR was performed using the Oxidative Stress PCR Array (PAMM-065) and p53 Signaling Pathway PCR Array (PAMM-027) according to the manufacturer's protocol (SABiosciences, Frederick, MD, USA). Briefly, FLT and GRD cDNA samples were mixed with $\mathrm{RT}^{2}$ SYBR Green qPCR Master Mix (SABiosciences, Frederick, MD, USA) and distributed across the 96-well plate array. Each of the 96-well plate arrays contained primers for 84 genes related to oxidative stress or $p 53$ signaling pathways and control housekeeping genes (HKG). PCR was performed in a thermal cycler (ABI 7500 Standard, Applied Biosystems, Foster City, CA, USA) with initial denaturation at $95^{\circ} \mathrm{C}$ for $10 \mathrm{~min}$, followed by 40 cycles of $95^{\circ} \mathrm{C}$ for $15 \mathrm{~s}$ and $60^{\circ} \mathrm{C}$ for one minute. FLT and GRD cDNA samples were also run on control RT ${ }^{2}$ RNA QC PCR Array plates (PAMM-999) to test RNA quality, reverse transcription efficiency, PCR efficiency and genomic DNA contamination.

\subsection{Nfe2l2 Real-Time PCR}

cDNA was synthesized by using QuantiTect Reverse Transcription Kit (Qiagen, Valencia, CA, USA). Briefly, $1 \mu \mathrm{g}$ of RNA sample was treated with gDNA Wipeout Buffer at $42{ }^{\circ} \mathrm{C}$ for $2 \mathrm{~min}$ then reverse-transcription was performed using Quantiscript RT Buffer and Quantiscript Reverse Transcriptase as per manufacturer's instruction. The Real-Time PCR mixture was made using QuantiTect SYBR Green PCR Kit (Qiagen, Valencia, CA, USA). Synthesized cDNA from the previous step was mixed with Quantiscript SYBR Green $\mathrm{PCR}$ Mix and $\mathrm{Nfe} 2 l 2$ primer mixture, per manufacturer's protocol. Real-time PCR was performed in a thermal cycler (ABI 7500 Standard, Applied Biosystems, Foster City, CA) with initial activation at $95{ }^{\circ} \mathrm{C}$ for $10 \mathrm{~min}$ followed by 40 cycles of $95{ }^{\circ} \mathrm{C}$ for $15 \mathrm{~s}$ and $60^{\circ} \mathrm{C}$ for $1 \mathrm{~min}$. Ct values were retrieved by maintaining the same threshold among all the samples.

\subsection{Data Analysis and Statistics}

For the Oxidative Stress PCR Array (PAMM-065) and $p 53$ Signaling Pathway PCR Array, relative expression levels of genes were calculated using the comparative threshold cycle method $(\triangle \Delta \mathrm{Ct})$ with normalization to the average expression levels of five housekeeping genes (SABiosciences Data Analysis Software). FLT samples were compared to GRD controls using Mann-Whitney U Test using $p<0.05$ as the threshold of significance and sample size of $\mathrm{n}=4$ mice per group.

For Nfe2l2 RT-PCR of heart samples, the change in expression levels were calculated using the $\Delta \Delta \mathrm{Ct}$ method with Hypoxanthine Phosphoribosyltransferase (Hprt) 1 as housekeeping gene. The log2 (linear) normalized expression from flight and ground control groups was used in the Mann-Whitney $\mathrm{U}$ test at $p<0.05, \mathrm{n}=4$ mice per group.

\subsection{Gene Network Predictions and Functional Analysis}

To generate predictions on potential protein interactions, statistically significant differentially expressed genes from both PCR arrays were entered into the String DB proteinprotein interaction database [75]. Experimental evidence, databases, and co-expression were used as sources to generate protein interaction networks. The interaction score was set to a threshold of "medium" (0.400).

Toppfun [76] was used to gain insight into whether the differentially expressed genes were linked to human disease phenotypes. Statistically significant differentially expressed genes were entered into the Toppfun database. The results were filtered using a Benjamini- 
Hochberg false discovery rate (FDR) threshold of $p<0.05$ and a query to genome overlap of four or more genes.

\section{Conclusions}

In conclusion, our study revealed that spaceflight significantly altered cardiac expression of genes related to cell cycle/growth (notably Cdkn1a/p21, Cdk1, and Myc), inflammation (notably Tnf) and oxidative stress (notably Nfe2l2, Nox1, Ptgs2), which may contribute to cardiac dysfunction. These findings provide novel data suitable for developing testable hypotheses for further study. Identification of specific mechanisms and molecules responsible for excess ROS generation during spaceflight is of considerable interest, and may yield new therapeutic approaches.

Supplementary Materials: The following are available online at https:/ /www.mdpi.com/article/ 10.3390/ijms22169088/s1.

Author Contributions: Conceptualization, R.K.G., E.A.C.A. and A.K.; data analysis, A.K. and C.G.T.T.; interpretation of results, R.K.G., E.A.C.A., A.K. and C.G.T.T.; writing-original draft preparation, A.K. and R.K.G.; writing-review and editing, R.K.G., E.A.C.A. and C.G.T.T.; supervision, R.K.G.; funding acquisition, R.K.G. and E.A.C.A. All authors have read and agreed to the published version of the manuscript.

Funding: This work was supported by a NASA Human Research Program grant (NNH04ZUU005N/RAD 2004-0000-0110) to R.K.G. and a NASA Space Biology grant (NNH08ZTT003N) to E.A.C.A. A.K. was a recipient of a NASA Space Biology Postdoctoral Fellowship award.

Institutional Review Board Statement: All animal procedures were conducted in accordance with guidelines described by the National Institute of Health Guide for Care and Use of Laboratory Animals, and approved by all relevant committees, including the Institutional Animal Care and Use Committee (IACUC) at National Aeronautics and Space Administration (NASA), Ames Research Center. Approval number: NAS-10-002-Y1.

Informed Consent Statement: Not applicable.

Data Availability Statement: All data associated with this study are provided in the main figures and tables and in the supplementary information.

Acknowledgments: The authors thank Michael Delp for tissue dissection, and Natalya Dvorochkin for technical assistance at the time of sample recovery. We are grateful to Hami Ray for editorial assistance and Bhupendra Soni (Celerim Solutions) for graphics shown in Figure 1.

Conflicts of Interest: The authors declare no conflict of interest.

\section{References}

1. Hughson, R.L.; Shoemaker, J.K.; Blaber, A.P.; Arbeille, P.; Greaves, D.K.; Pereira-Junior, P.P.; Xu, D. Cardiovascular regulation during long-duration spaceflights to the International Space Station. J. Appl. Physiol. 2012, 112, 719-727. [CrossRef] [PubMed]

2. Demontis, G.C.; Germani, M.M.; Caiani, E.G.; Barravecchia, I.; Passino, C.; Angeloni, D. Human Pathophysiological Adaptations to the Space Environment. Front. Physiol. 2017, 8, 547. [CrossRef] [PubMed]

3. Marshall-Goebel, K.; Laurie, S.S.; Alferova, I.V.; Arbeille, P.; Aunon-Chancellor, S.M.; Ebert, D.J.; Lee, S.M.C.; Macias, B.R.; Martin, D.S.; Pattarini, J.M.; et al. Assessment of jugular venous blood flow stasis and thrombosis during spaceflight. JAMA Netw. Open 2019, 2, e1915011. [CrossRef] [PubMed]

4. Buckey, J.C., Jr.; Gaffney, F.A.; Lane, L.D.; Levine, B.D.; Watenpaugh, D.E.; Wright, S.J.; Yancy, C.W., Jr.; Meyer, D.M.; Blomqvist, C.G. Central venous pressure in space. J. Appl. Physiol. 1996, 81, 19-25. [CrossRef]

5. Moore, T.P.; Thornton, W.E. Space shuttle inflight and postflight fluid shifts measured by leg volume changes. Aviat. Space Environ. Med. 1987, 58, A91-A96.

6. Vernice, N.A.; Meydan, C.; Afshinnekoo, E.; Mason, C.E. Long-term spaceflight and the cardiovascular system. Precis. Clin. Med. 2020, 3, 284-291. [CrossRef]

7. Wieling, W.; Halliwill, J.R.; Karemaker, J.M. Orthostatic intolerance after space flight. J. Physiol. 2002, 538, 1. [CrossRef]

8. Gallo, C.; Ridolfi, L.; Scarsoglio, S. Cardiovascular deconditioning during long-term spaceflight through multiscale modeling. NPJ Microgravity 2020, 6, 27. [CrossRef]

9. MacNamara, J.P.; Dias, K.A.; Sarma, S.; Lee, S.M.C.; Martin, D.; Romeijn, M.; Zaha, V.G.; Levine, B.D. Cardiac effects of repeated weightlessness during extreme duration swimming compared with spaceflight. Circulation 2021, 143, 1533-1535. [CrossRef] 
10. Perhonen, M.A.; Franco, F.; Lane, L.D.; Buckey, J.C.; Blomqvist, C.G.; Zerwekh, J.E.; Peshock, R.M.; Weatherall, P.T.; Levine, B.D. Cardiac atrophy after bed rest and spaceflight. J. Appl. Physiol. 2001, 91, 645-653. [CrossRef]

11. Summers, R.L.; Martin, D.S.; Meck, J.V.; Coleman, T.G. Mechanism of spaceflight-induced changes in left ventricular mass. Am. J. Cardiol. 2005, 95, 1128-1130. [CrossRef]

12. Goldstein, M.A.; Edwards, R.J.; Schroeter, J.P. Cardiac morphology after conditions of microgravity during COSMOS 2044. J. Appl. Physiol. 1992, 73, 94S-100S. [CrossRef] [PubMed]

13. Ray, C.A.; Vasques, M.; Miller, T.A.; Wilkerson, M.K.; Delp, M.D. Effect of short-term microgravity and long-term hindlimb unloading on rat cardiac mass and function. J. Appl. Physiol. 2001, 91, 1207-1213. [CrossRef]

14. Liang, L.; Li, H.; Cao, T.; Qu, L.; Zhang, L.; Fan, G.C.; Greer, P.A.; Li, J.; Jones, D.L.; Peng, T. Calpain activation mediates microgravity-induced myocardial abnormalities in mice via p38 and ERK1/2 MAPK pathways. J. Biol. Chem. 2020, 295, 16840-16851. [CrossRef]

15. Wang, X.P.; Xing, C.Y.; Zhang, J.X.; Zhou, J.H.; Li, Y.C.; Yang, H.Y.; Zhang, P.F.; Zhang, W.; Huang, Y.; Long, J.G.; et al. Timerestricted feeding alleviates cardiac dysfunction induced by simulated microgravity via restoring cardiac FGF21 signaling. FASEB J. 2020, 34, 15180-15196. [CrossRef] [PubMed]

16. Coleman, M.A.; Sasi, S.P.; Onufrak, J.; Natarajan, M.; Manickam, K.; Schwab, J.; Muralidharan, S.; Peterson, L.E.; Alekseyev, Y.O.; Yan, X.; et al. Low-dose radiation affects cardiac physiology: Gene networks and molecular signaling in cardiomyocytes. Am. J. Physiol. Heart Circ. Physiol. 2015, 309, H1947-H1963. [CrossRef] [PubMed]

17. Seawright, J.W.; Samman, Y.; Sridharan, V.; Mao, X.W.; Cao, M.; Singh, P.; Melnyk, S.; Koturbash, I.; Nelson, G.A.; Hauer-Jensen, M.; et al. Effects of low-dose rate gamma-irradiation combined with simulated microgravity on markers of oxidative stress, DNA methylation potential, and remodeling in the mouse heart. PLoS ONE 2017, 12, e0180594. [CrossRef] [PubMed]

18. Beheshti, A.; McDonald, J.T.; Miller, J.; Grabham, P.; Costes, S.V. GeneLab database analyses suggest long-term impact of space radiation on the cardiovascular system by the activation of FYN through reactive oxygen species. Int. J. Mol. Sci. 2019, $20,661$. [CrossRef] [PubMed]

19. Baqai, F.P.; Gridley, D.S.; Slater, J.M.; Luo-Owen, X.; Stodieck, L.S.; Ferguson, V.; Chapes, S.K.; Pecaut, M.J. Effects of spaceflight on innate immune function and antioxidant gene expression. J. Appl. Physiol. 2009, 106, 1935-1942. [CrossRef]

20. Afanas'ev, I. ROS and RNS signaling in heart disorders: Could antioxidant treatment be successful? Oxid. Med. Cell Longev. 2011, 2011, 293769. [CrossRef]

21. Rizzo, A.M.; Corsetto, P.A.; Montorfano, G.; Milani, S.; Zava, S.; Tavella, S.; Cancedda, R.; Berra, B. Effects of long-term space flight on erythrocytes and oxidative stress of rodents. PLoS ONE 2012, 7, e32361. [CrossRef]

22. Barrila, J.; Ott, C.M.; LeBlanc, C.; Mehta, S.K.; Crabbe, A.; Stafford, P.; Pierson, D.L.; Nickerson, C.A. Spaceflight modulates gene expression in the whole blood of astronauts. NPJ Microgravity 2016, 2, 16039. [CrossRef]

23. Tauber, S.; Christoffel, S.; Thiel, C.S.; Ullrich, O. Transcriptional homeostasis of oxidative stress-related pathways in altered gravity. Int. J. Mol. Sci. 2018, 19, 2814. [CrossRef]

24. Garrett-Bakelman, F.E.; Darshi, M.; Green, S.J.; Gur, R.C.; Lin, L.; Macias, B.R.; McKenna, M.J.; Meydan, C.; Mishra, T.; Nasrini, J.; et al. The NASA Twins Study: A multidimensional analysis of a year-long human spaceflight. Science 2019, 364. [CrossRef]

25. Overbey, E.G.; da Silveira, W.A.; Stanbouly, S.; Nishiyama, N.C.; Roque-Torres, G.D.; Pecaut, M.J.; Zawieja, D.C.; Wang, C.; Willey, J.S.; Delp, M.D.; et al. Spaceflight influences gene expression, photoreceptor integrity, and oxidative stress-related damage in the murine retina. Sci. Rep. 2019, 9, 13304. [CrossRef] [PubMed]

26. da Silveira, W.A.; Fazelinia, H.; Rosenthal, S.B.; Laiakis, E.C.; Kim, M.S.; Meydan, C.; Kidane, Y.; Rathi, K.S.; Smith, S.M.; Stear, B.; et al. Comprehensive multi-omics analysis reveals mitochondrial stress as a central biological hub for spaceflight impact. Cell 2020, 183, 1185-1201.e1120. [CrossRef] [PubMed]

27. Chakraborty, N.; Waning, D.L.; Gautam, A.; Hoke, A.; Sowe, B.; Youssef, D.; Butler, S.; Savaglio, M.; Childress, P.J.; Kumar, R.; et al. Gene-Metabolite network linked to inhibited bioenergetics in association with spaceflight-induced loss of male mouse quadriceps muscle. J. Bone Miner. Res. 2020, 35, 2049-2057. [CrossRef] [PubMed]

28. Ohnishi, T.; Inoue, N.; Matsumoto, H.; Omatsu, T.; Ohira, Y.; Nagaoka, S. Cellular content of p53 protein in rat skin after exposure to the space environment. J. Appl. Physiol. 1996, 81, 183-185. [CrossRef]

29. Lu, T.; Zhang, Y.; Kidane, Y.; Feiveson, A.; Stodieck, L.; Karouia, F.; Ramesh, G.; Rohde, L.; Wu, H. Cellular responses and gene expression profile changes due to bleomycin-induced DNA damage in human fibroblasts in space. PLoS ONE 2017, 12, e0170358. [CrossRef] [PubMed]

30. Blaber, E.A.; Dvorochkin, N.; Lee, C.; Alwood, J.S.; Yousuf, R.; Pianetta, P.; Globus, R.K.; Burns, B.P.; Almeida, E.A. Microgravity induces pelvic bone loss through osteoclastic activity, osteocytic osteolysis, and osteoblastic cell cycle inhibition by CDKN1a/p21. PLoS ONE 2013, 8, e61372. [CrossRef] [PubMed]

31. Hammond, T.G.; Allen, P.L.; Birdsall, H.H. Effects of space flight on mouse liver versus kidney: Gene pathway analyses. Int. J. Mol. Sci. 2018, 19, 4106. [CrossRef] [PubMed]

32. Behnke, B.J.; Stabley, J.N.; McCullough, D.J.; Davis, R.T., 3rd; Dominguez, J.M., 2nd; Muller-Delp, J.M.; Delp, M.D. Effects of spaceflight and ground recovery on mesenteric artery and vein constrictor properties in mice. FASEB J. 2013, 27, 399-409. [CrossRef] [PubMed]

33. Bailey, J.F.; Hargens, A.R.; Cheng, K.K.; Lotz, J.C. Effect of microgravity on the biomechanical properties of lumbar and caudal intervertebral discs in mice. J. Biomech. 2014, 47, 2983-2988. [CrossRef] [PubMed] 
34. Connor, M.K.; Hood, D.A. Effect of microgravity on the expression of mitochondrial enzymes in rat cardiac and skeletal muscles. J. Appl. Physiol. 1998, 84, 593-598. [CrossRef] [PubMed]

35. Ogneva, I.V.; Loktev, S.S.; Sychev, V.N. Cytoskeleton structure and total methylation of mouse cardiac and lung tissue during space flight. PLoS ONE 2018, 13, e0192643. [CrossRef]

36. Walls, S.; Diop, S.; Birse, R.; Elmen, L.; Gan, Z.; Kalvakuri, S.; Pineda, S.; Reddy, C.; Taylor, E.; Trinh, B.; et al. Prolonged exposure to microgravity reduces cardiac contractility and initiates remodeling in Drosophila. Cell Rep. 2020, 33, 108445. [CrossRef]

37. Camberos, V.; Baio, J.; Mandujano, A.; Martinez, A.F.; Bailey, L.; Hasaniya, N.; Kearns-Jonker, M. The impact of spaceflight and microgravity on the human islet-1+ cardiovascular progenitor cell transcriptome. Int. J. Mol. Sci. 2021, 22, 3577. [CrossRef]

38. Blaber, E.A.; Pecaut, M.J.; Jonscher, K.R. Spaceflight activates autophagy programs and the proteasome in mouse liver. Int. J. Mol. Sci. 2017, 18, 2062. [CrossRef]

39. Suzuki, T.; Uruno, A.; Yumoto, A.; Taguchi, K.; Suzuki, M.; Harada, N.; Ryoke, R.; Naganuma, E.; Osanai, N.; Goto, A.; et al. Nrf2 contributes to the weight gain of mice during space travel. Commun. Biol. 2020, 3, 496. [CrossRef]

40. Hayashi, T.; Kudo, T.; Fujita, R.; Fujita, S.I.; Tsubouchi, H.; Fuseya, S.; Suzuki, R.; Hamada, M.; Okada, R.; Muratani, M.; et al. Nuclear factor E2-related factor 2 (NRF2) deficiency accelerates fast fibre type transition in soleus muscle during space flight. Commun. Biol. 2021, 4, 787. [CrossRef]

41. Lambeth, J.D.; Neish, A.S. Nox enzymes and new thinking on reactive oxygen: A double-edged sword revisited. Annu. Rev. Pathol. 2014, 9, 119-145. [CrossRef]

42. Bedard, K.; Krause, K.H. The NOX family of ROS-generating NADPH oxidases: Physiology and pathophysiology. Physiol. Rev. 2007, 87, 245-313. [CrossRef] [PubMed]

43. Brandes, R.P.; Weissmann, N.; Schroder, K. NADPH oxidases in cardiovascular disease. Free Radic. Biol. Med. 2010, 49, 687-706. [CrossRef] [PubMed]

44. Liang, L.; Yuan, W.; Qu, L.; Li, H.; Zhang, L.; Fan, G.C.; Peng, T. Administration of losartan preserves cardiomyocyte size and prevents myocardial dysfunction in tail-suspended mice by inhibiting p47(phox) phosphorylation, NADPH oxidase activation and MuRF1 expression. J. Transl. Med. 2019, 17, 279. [CrossRef] [PubMed]

45. Wang, D.; Patel, V.V.; Ricciotti, E.; Zhou, R.; Levin, M.D.; Gao, E.; Yu, Z.; Ferrari, V.A.; Lu, M.M.; Xu, J.; et al. Cardiomyocyte cyclooxygenase-2 influences cardiac rhythm and function. Proc. Natl. Acad. Sci. USA 2009, 106, 7548-7552. [CrossRef] [PubMed]

46. Sellers, R.S.; Radi, Z.A.; Khan, N.K. Pathophysiology of cyclooxygenases in cardiovascular homeostasis. Vet. Pathol. 2010, 47, 601-613. [CrossRef]

47. Hughes-Fulford, M.; Rodenacker, K.; Jutting, U. Reduction of anabolic signals and alteration of osteoblast nuclear morphology in microgravity. J. Cell. Biochem. 2006, 99, 435-449. [CrossRef]

48. Bondesen, B.A.; Mills, S.T.; Pavlath, G.K. The COX-2 pathway regulates growth of atrophied muscle via multiple mechanisms. Am. J. Physiol. Cell Physiol. 2006, 290, C1651-C1659. [CrossRef]

49. Nakai, K.; Tanaka, S.; Sakai, A.; Nagashima, M.; Tanaka, M.; Otomo, H.; Nakamura, T. Cyclooxygenase-2 selective inhibition suppresses restoration of tibial trabecular bone formation in association with restriction of osteoblast maturation in skeletal reloading after hindlimb elevation of mice. Bone 2006, 39, 83-92. [CrossRef]

50. Nishiyama, A.; Matsui, M.; Iwata, S.; Hirota, K.; Masutani, H.; Nakamura, H.; Takagi, Y.; Sono, H.; Gon, Y.; Yodoi, J. Identification of thioredoxin-binding protein-2/vitamin $\mathrm{D}(3)$ up-regulated protein 1 as a negative regulator of thioredoxin function and expression. J. Biol. Chem. 1999, 274, 21645-21650. [CrossRef]

51. Versari, S.; Longinotti, G.; Barenghi, L.; Maier, J.A.; Bradamante, S. The challenging environment on board the International Space Station affects endothelial cell function by triggering oxidative stress through thioredoxin interacting protein overexpression: The ESA-SPHINX experiment. FASEB J. 2013, 27, 4466-4475. [CrossRef]

52. Saadatzadeh, M.R.; Bijangi-Vishehsaraei, K.; Hong, P.; Bergmann, H.; Haneline, L.S. Oxidant hypersensitivity of Fanconi anemia type C-deficient cells is dependent on a redox-regulated apoptotic pathway. J. Biol. Chem. 2004, 279, 16805-16812. [CrossRef]

53. Galow, A.M.; Wolfien, M.; Muller, P.; Bartsch, M.; Brunner, R.M.; Hoeflich, A.; Wolkenhauer, O.; David, R.; Goldammer, T. Integrative cluster analysis of whole hearts reveals proliferative cardiomyocytes in adult mice. Cells 2020, 9, 1144. [CrossRef]

54. Tong, Y.F.; Wang, Y.; Ding, Y.Y.; Li, J.M.; Pan, X.C.; Lu, X.L.; Chen, X.H.; Liu, Y.; Zhang, H.G. Cyclin-Dependent Kinase Inhibitor p21WAF1/CIP1 facilitates the development of cardiac hypertrophy. Cell Physiol. Biochem. 2017, 42, 1645-1656. [CrossRef]

55. Xu, M.; Wan, C.X.; Huang, S.H.; Wang, H.B.; Fan, D.; Wu, H.M.; Wu, Q.Q.; Ma, Z.G.; Deng, W.; Tang, Q.Z. Oridonin protects against cardiac hypertrophy by promoting P21-related autophagy. Cell Death Dis. 2019, 10, 403. [CrossRef] [PubMed]

56. Huang, S.; Xu, M.; Liu, L.; Yang, J.; Wang, H.; Wan, C.; Deng, W.; Tang, Q. Autophagy is involved in the protective effect of p21 on LPS-induced cardiac dysfunction. Cell Death Dis. 2020, 11, 554. [CrossRef]

57. Hauck, L.; Grothe, D.; Billia, F. p21(CIP1/WAF1)-dependent inhibition of cardiac hypertrophy in response to Angiotensin II involves Akt/Myc and pRb signaling. Peptides 2016, 83, 38-48. [CrossRef]

58. Burton, P.B.; Yacoub, M.H.; Barton, P.J. Cyclin-dependent kinase inhibitor expression in human heart failure. A comparison with fetal development. Eur. Heart J. 1999, 20, 604-611. [CrossRef]

59. Pei, L.; Melmed, S. Isolation and characterization of a pituitary tumor-transforming gene (PTTG). Mol. Endocrinol. 1997, 11, 433-441. [CrossRef]

60. Hoglund, A.; Stromvall, K.; Li, Y.; Forshell, L.P.; Nilsson, J.A. Chk2 deficiency in Myc overexpressing lymphoma cells elicits a synergistic lethal response in combination with PARP inhibition. Cell Cycle 2011, 10, 3598-3607. [CrossRef] 
61. Seawright, J.W.; Sridharan, V.; Landes, R.D.; Cao, M.; Singh, P.; Koturbash, I.; Mao, X.W.; Miousse, I.R.; Singh, S.P.; Nelson, G.A.; et al. Effects of low-dose oxygen ions and protons on cardiac function and structure in male C57BL/6J mice. Life Sci. Space Res. 2019, 20, 72-84. [CrossRef] [PubMed]

62. Prasad, B.; Grimm, D.; Strauch, S.M.; Erzinger, G.S.; Corydon, T.J.; Lebert, M.; Magnusson, N.E.; Infanger, M.; Richter, P.; Kruger, M. Influence of microgravity on apoptosis in cells, tissues, and other systems in vivo and in vitro. Int. J. Mol. Sci. 2020, 21, 9373. [CrossRef] [PubMed]

63. Congdon, C.C.; Allebban, Z.; Gibson, L.A.; Kaplansky, A.; Strickland, K.M.; Jago, T.L.; Johnson, D.L.; Lange, R.D.; Ichiki, A.T. Lymphatic tissue changes in rats flown on Spacelab Life Sciences-2. J. Appl. Physiol. 1996, 81, 172-177. [CrossRef] [PubMed]

64. Gridley, D.S.; Mao, X.W.; Stodieck, L.S.; Ferguson, V.L.; Bateman, T.A.; Moldovan, M.; Cunningham, C.E.; Jones, T.A.; Slater, J.M.; Pecaut, M.J. Changes in mouse thymus and spleen after return from the STS-135 mission in space. PLoS ONE 2013, 8, e75097. [CrossRef] [PubMed]

65. Locksley, R.M.; Killeen, N.; Lenardo, M.J. The TNF and TNF receptor superfamilies: Integrating mammalian biology. Cell 2001, 104, 487-501. [CrossRef]

66. Gridley, D.S.; Slater, J.M.; Luo-Owen, X.; Rizvi, A.; Chapes, S.K.; Stodieck, L.S.; Ferguson, V.L.; Pecaut, M.J. Spaceflight effects on T lymphocyte distribution, function and gene expression. J. Appl. Physiol. 2009, 106, 194-202. [CrossRef]

67. Crucian, B.; Stowe, R.P.; Mehta, S.; Quiriarte, H.; Pierson, D.; Sams, C. Alterations in adaptive immunity persist during long-duration spaceflight. NPJ Microgravity 2015, 1, 15013. [CrossRef]

68. Chang, T.T.; Walther, I.; Li, C.F.; Boonyaratanakornkit, J.; Galleri, G.; Meloni, M.A.; Pippia, P.; Cogoli, A.; Hughes-Fulford, M. The Rel/NF-kappaB pathway and transcription of immediate early genes in T cell activation are inhibited by microgravity. J. Leukoc. Biol. 2012, 92, 1133-1145. [CrossRef]

69. Gertz, M.L.; Chin, C.R.; Tomoiaga, D.; MacKay, M.; Chang, C.; Butler, D.; Afshinnekoo, E.; Bezdan, D.; Schmidt, M.A.; Mozsary, C.; et al. Multi-omic, single-cell, and biochemical profiles of astronauts guide Pharmacological strategies for returning to gravity. Cell Rep. 2020, 33, 108429. [CrossRef]

70. Sasi, S.P.; Yan, X.; Zuriaga-Herrero, M.; Gee, H.; Lee, J.; Mehrzad, R.; Song, J.; Onufrak, J.; Morgan, J.; Enderling, H.; et al. Different sequences of fractionated low-dose proton and single iron-radiation-induced divergent biological responses in the heart. Radiat. Res. 2017, 188, 191-203. [CrossRef]

71. Garikipati, V.N.S.; Arakelyan, A.; Blakely, E.A.; Chang, P.Y.; Truongcao, M.M.; Cimini, M.; Malaredy, V.; Bajpai, A.; Addya, S.; Bisserier, M.; et al. Long-term effects of very low dose particle radiation on gene expression in the heart: Degenerative disease risks. Cells 2021, 10, 387. [CrossRef]

72. Hughson, R.L.; Robertson, A.D.; Arbeille, P.; Shoemaker, J.K.; Rush, J.W.; Fraser, K.S.; Greaves, D.K. Increased postflight carotid artery stiffness and inflight insulin resistance resulting from 6-mo spaceflight in male and female astronauts. Am. J. Physiol. Heart Circ. Physiol. 2016, 310, H628-H638. [CrossRef]

73. Mehta, S.K.; Laudenslager, M.L.; Stowe, R.P.; Crucian, B.E.; Feiveson, A.H.; Sams, C.F.; Pierson, D.L. Latent virus reactivation in astronauts on the international space station. NPJ Microgravity 2017, 3, 11. [CrossRef]

74. Roberts, D.R.; Inglesby, D.C.; Brown, T.R.; Collins, H.R.; Eckert, M.A.; Asemani, D. Longitudinal change in ventricular volume is accelerated in astronauts undergoing long-duration spaceflight. Aging Brain 2021, 1, 100017. [CrossRef]

75. Szklarczyk, D.; Gable, A.L.; Nastou, K.C.; Lyon, D.; Kirsch, R.; Pyysalo, S.; Doncheva, N.T.; Legeay, M.; Fang, T.; Bork, P.; et al. The STRING database in 2021: Customizable protein-protein networks, and functional characterization of user-uploaded gene/measurement sets. Nucleic Acids Res. 2021, 49, D605-D612. [CrossRef]

76. Chen, J.; Bardes, E.E.; Aronow, B.J.; Jegga, A.G. ToppGene Suite for gene list enrichment analysis and candidate gene prioritization. Nucleic Acids Res. 2009, 37, W305-W311. [CrossRef] 